Illinois State University

ISU ReD: Research and eData

Theses and Dissertations

3-24-2021

\title{
Perceptions Of Residents Living In A Food Desert On The Impact Of A Community-Supported Agriculture Pilot Program
}

Jessica Thome

Illinois State University, jethome@ilstu.edu

Follow this and additional works at: https://ir.library.illinoisstate.edu/etd

Part of the Nutrition Commons, and the Public Health Education and Promotion Commons

\section{Recommended Citation}

Thome, Jessica, "Perceptions Of Residents Living In A Food Desert On The Impact Of A CommunitySupported Agriculture Pilot Program" (2021). Theses and Dissertations. 1418.

https://ir.library.illinoisstate.edu/etd/1418

This Thesis is brought to you for free and open access by ISU ReD: Research and eData. It has been accepted for inclusion in Theses and Dissertations by an authorized administrator of ISU ReD: Research and eData. For more information, please contact ISUReD@ilstu.edu. 


\section{PERCEPTIONS OF RESIDENTS LIVING IN A FOOD DESERT ON THE IMPACT OF A COMMUNITY-SUPPORTED AGRICULTURE PILOT PROGRAM}

\section{JESSICA THOME}

\section{Pages}

Objective: The purpose of the study was to examine perspectives on food access among a low-income, food desert community through participation in a grant funded CSA program.

Design: Healthy Eating Program is a pilot program assessing the effect of a CSA intervention on health among residents living in a food desert. Participants were surveyed through an initial survey and final survey with questions regarding perceived health status and daily food stressors. Data was collected through Qualtrics and analyzed using SPSS.

Setting: Low-income, food desert community residing in the Westside of Bloomington, Illinois. Participants: Forty participants 18 years or older, low-income and residing within the Westside. Results: Perceived health status of individuals increased significantly throughout the program as did participants skipping fewer meals. However, having enough time to cook healthy meals and shopping budget for other food did not significantly change. Access to fresh produce is a motivation for participants to eat better, cook at home more often and feel healthier but does not necessarily correlate to less food stress in participant's lives.

Conclusions: The CSA program increased access to fruits and vegetables for this low-income community; however, the fresh produce is logistically difficult for participants due to time and budget constraints. CSA programs grant access and improve perceptions of health but do not help with stress of food such as affordability for other products, convenience, and knowledge on unfamiliar foods. Future programs should provide more flexible logistics, education on prepping, 
cooking and storing the new vegetables and attempt to utilize additional measures to assess

health outcomes.

KEYWORDS: community-supported agriculture; low-income; food desert; health; food stressors 


\title{
PERCEPTIONS OF RESIDENTS LIVING IN A FOOD DESERT ON THE IMPACT OF A COMMUNITY-SUPPORTED AGRICULTURE PILOT PROGRAM
}

JESSICA THOME

\author{
A Thesis Submitted in Partial \\ Fulfillment of the Requirements \\ for the Degree of \\ MASTER OF SCIENCE \\ Department of Family and Consumer Sciences \\ ILLINOIS STATE UNIVERSITY
}


(C) 2021 Jessica Thome 


\title{
PERCEPTIONS OF RESIDENTS LIVING IN A FOOD DESERT ON THE IMPACT OF A COMMUNITY-SUPPORTED AGRICULTURE PILOT PROGRAM
}

\author{
JESSICA THOME
}

COMMITTEE MEMBERS:

Julie Schumacher, Chair

Jennifer Barnes

Deborah Halperin 


\section{ACKNOWLEDGMENTS}

The writer wishes to express her appreciation to her thesis chair, Dr. Julie Schumacher for her guidance throughout the research process. Dr. Jennifer Barnes, thank you for your support with data analysis and your assistance throughout the process. A sincere thank you goes to Deborah Halperin, without you and your tireless efforts in West Bloomington this thesis would have never come to fruition. And a special shoutout to the writer's sister Morgan, your hours spent editing and motivating do not go unnoticed.

J. T. 


\section{CONTENTS}

Page

ACKNOWLEDGMENTS

TABLES iv

CHAPTER I: PERCEPTIONS OF RESIDENTS LIVING IN A FOOD DESERT ON THE

IMPACT OF A COMMUNITY-SUPPORTED AGRICULTURE PILOT PROGRAM 1

$\begin{array}{ll}\text { Introduction } & 1\end{array}$

Methods 3

$\begin{array}{ll}\text { Sample } & 3\end{array}$

$\begin{array}{ll}\text { Procedures } & 4\end{array}$

$\begin{array}{ll}\text { Instrumentation } & 5\end{array}$

$\begin{array}{ll}\text { Data Analysis } & 6\end{array}$

$\begin{array}{ll}\text { Results } & 6\end{array}$

$\begin{array}{ll}\text { Participants } & 6\end{array}$

Results of Participants that Completed Both Surveys $\quad 7$

$\begin{array}{lr}\text { Results of Final Survey } & 8\end{array}$

$\begin{array}{ll}\text { Discussion } & 10\end{array}$

$\begin{array}{ll}\text { Limitations } & 12\end{array}$

$\begin{array}{ll}\text { Conclusion } & 14\end{array}$

$\begin{array}{ll}\text { REFERENCES } & 17\end{array}$

CHAPTER II: EXTENDED REVIEW OF LITERATURE PERCEPTIONS OF RESIDENTS

LIVING IN A FOOD DESERT ON THE IMPACT OF A COMMUNITY-SUPPORTED

AGRICULTURE PILOT PROGRAM 19 
Defining Food Desert Communities 19

Impacts of Past Food Desert Interventions $\quad 20$

Focusing on Health in Food Deserts $\quad 22$

Impact of Educational Information $\quad 25$

New Efforts in Food Deserts $\quad 26$

REFERENCES

APPENDIX A: QUESTIONNAIRE FOR INTERESTED PARTICIPANTS OF HEALTHY

$\begin{array}{ll}\text { EATING PROGRAM } & 35\end{array}$

$\begin{array}{ll}\text { APPENDIX B: INITIAL SURVEY } & 37\end{array}$

APPENDIX C: FINAL SURVEY 40

APPENDIX D: RECRUITMENT EMAIL

APPENDIX E: INFORMED CONSENT 


\section{TABLES}

Table

Page

1. Participant Demographics of those Completing the Entire Healthy Eating Program 15

2. Initial Compared to Final Responses for Participants Completing Entire Program 


\section{CHAPTER I: PERCEPTIONS OF RESIDENTS LIVING IN A FOOD DESERT ON THE IMPACT OF A COMMUNITY-SUPPORTED AGRICULTURE PILOT PROGRAM}

\section{Introduction}

Community-Supported Agriculture (CSA) programs are an effective way to incorporate nutrition into homes all across the world. Creating a sustainable avenue for fresh produce to be in homes is one way to build healthier and more food secure communities. Studies show that people who incorporate more fruits and vegetables in their diet on a regular basis are more likely to have a reduced risk of chronic disease (Aune et al. 2018; Boeing et al. 2012; USDA MyPlate, 2020). Additionally, people who are food-insecure are more likely to have decreased nutrient intakes, increased rates of mental health problems, diabetes and overall, in poor or fair health (Gundersen \& Ziliak, 2015). Therefore, it is vital for low-income, food desert communities to gain access to consistent fresh produce in order to create more food security and improve overall health.

Bloomington is a central Illinois city located in McLean County and, even though it is one of the most agriculturally rich areas in the state (City of Bloomington: About, 2020), 13.3\% of the population lives in poverty which is $2.8 \%$ higher than the national average (Data USA, 2017 \& US Census, 2020). West Bloomington is currently considered a food desert by the United States Department of Agriculture, and this inability for West Bloomington residents to access affordable, healthy food options has led to impediments regarding overall health.

Community-Supported Agriculture (CSA) has become popular in recent years as an avenue to improve the health status of consumers. CSA is a program designed for consumers to buy shares of a farm's harvest in advance of the crop's season, which leads to many benefits for both farmers and consumers. Farmers benefit by earning payment early in their season, which 
not only helps with the farm's cash flow, but also provides an opportunity to create a strong sense of community by getting to know their consumers (Local Harvest, 2020). In turn, consumers get to try new vegetables, recipes, and they also have a constant source of fresh produce that provides nutritional benefits. Although CSA shares have been around since the 1960s, they have become more popular in recent years. However, they are still not economically feasible for low-income families. An average CSA share per pick-up is $\$ 22.28$ (Hawthorne Valley, 2014), but a consumer typically has to pay upfront for the entire season. Depending on the farm or the season, the program could last 22-26 weeks, which puts the price at about $\$ 500$ $\$ 600$ per share, an inaccessible expense for many low-income families to pay for at one time.

While there has been a great deal of research focused on food deserts in the United States and even more research on the benefits of a healthy diet, there is limited research on the impact a CSA program can have on food desert communities with a large portion of low-income residents. The purpose of this study was to examine the value that access to fresh produce provided by a CSA has on a low-income, food desert community.

The Healthy Eating Program was developed as an intervention in the West Side of Bloomington. This pilot program assessed the benefits of consistent access to fresh produce, how fresh produce impacts health and daily food stressors of participants, and whether a CSA program could be a practical intervention in a low-income community. The independent variable, vegetable bag, is defined as a free, weekly bag full of fresh vegetables and herbs from PrairiErth CSA partnership. The dependent variables included the perceptions held by the West Side community members regarding incorporation of fresh produce and whether free vegetable bags improved their health and daily food stressors. Health is defined in accordance with the World Health Organization (2021) definition "Healthy is a state of complete physical, mental, 
and social well-being and not merely the absence of disease or infirmity." Health was measured by participants' intake of vegetables, how often participants ate at home in a week, and the participants' overall perspective of their health. Food stressors were measured by participants' response to food being less of a worry within the household, if the free vegetables helped their grocery budget, and the participants' overall perception of the program. The following research questions guided this study: 1. Can programs like the Healthy Eating Program benefit lowincome, food desert communities, specifically with their health and daily food stressors? 2. Can CSA programs be an effective intervention for a food desert?

\section{Methods}

\section{Sample}

The population consisted of 40 participants who qualified for this study through the inclusion criteria of being low-income (180\% of the poverty line), at least 18 years old, living in the West Side of Bloomington, IL, and available for vegetable bag pick up every Wednesday for the 25 -week program. The 40 participants chosen were the first 40 participants to meet these qualifications and submit their questionnaire indicating their interest. In total, there were 114 responses, and 77 (67.5\%) qualified for the program. The questionnaire was available through the West Bloomington Revitalization Project (WBRP) website and Facebook page and was forwarded to key stakeholders in schools, churches, and businesses across the West Side. Out of the 40 initial participants, seven $(17.5 \%)$ were men and the other thirty-three $(82.5 \%)$ were women. 


\section{Procedures}

The West Bloomington Revitalization Project (WBRP) applied for a grant through the John M. Scott Foundation to provide free CSA shares to 40 participants. John M. Scott Foundation's policy is “under the parameters of the Trust, grantees must advance health equity by supporting social determinants of health for income qualified McLean County residents" (City of Bloomington: JMS, 2020). The WBRP was granted $\$ 40,000$ during the 2020 year to be used for the Healthy Eating Program and to update the kitchen at the WBRP. Forty CSA shares were purchased for the span of 25 weeks at a cost of $\$ 485$ per share.

The study was conducted by providing weekly vegetable bags to the 40 identified participants starting in May and ending in November. The vegetable bag handouts took place at WBRP, which is located in the center of West Bloomington and is a home to many community resources for the residents of the West Side. Vegetable bag handouts occurred every Wednesday night between 6:00 pm and 7:30 pm. The starting date of the program was May 20, 2020 and ended November 4, 2020. Due to Covid-19, the pickups occurred by drive through. Masked volunteers placed vegetable bags into cars while participants stayed in their cars. Participants of the study had the option to partake in surveys throughout the program, but this was not required for the participants to receive vegetable bags.

A Facebook group was created for all families that were part of the program to connect with other participants, share recipes and ask questions. The program also partnered with community outreach programs to provide beneficial information to the participants of the program such as voting registration, free nutrition consults, access to community gardens, easyto-make recipes and other opportunities to join WBRP programs. Text, email, and Facebook 
message reminders went out to the participants each week to remind them of pickup and other events and resources being offered for the week.

The 40 participants were chosen on a first come first serve basis. The first 40 to meet the requirements were emailed consent forms for the research and contracts which committed the participants to do the 25-week pickup. A waitlist was created for people who met the requirements but were not one of the first 40 people to fill out the questionnaire and be approved. Within the contract, it was stated that if a participant missed three or more pickups, they would be removed from the list and someone from the waiting list would take their spot. Participants had the opportunity to assign other friends or family to do pickups. Attendance was documented weekly at vegetable bag pickups. Surveys were sent out online and were anonymously collected through Qualtrics Software. Prior to the first pickup in May, the first survey was sent to all participants via email. The final survey was sent out at the end of October 2020.

\section{Instrumentation}

Pre-program questionnaires were distributed online and through local stakeholders between March and April. The questionnaire contained 12 questions that asked demographic information to confirm that each interested participant qualified for the program. The questionnaire took less than 5 minutes to complete. The questionnaire can be found in Appendix A. At the beginning of the program in May, the initial survey was sent out. The initial survey asked questions about the participants interest in the program and assessed the participants' personal experiences with health and food related concerns within their household. The survey contained 16 questions and included multiple choice and short answer questions. It took participants about 15 minutes to complete the survey. The initial survey can be found in 
Appendix B. The final survey in October repeated questions from the initial survey in order to see the trends the group as a whole had made with consumption of fresh produce, eating at home, and overall health. The final survey contained 23 questions and once again included multiple choice and short answer questions. It took participants about 15 minutes to complete. The final can be found in Appendix C.

\section{Data Analysis}

Statistical Software Package (SPSS) version 14.0 was used to analyze all quantitative data. The quantitative questions were assigned numerical values in order to help with the analysis of the information using the statistical software. The initial and final surveys were analyzed to assess if there was significant difference in the vegetable consumption, overall health and daily food stressors of the participants. A paired T-test was used to compare the participants that completed both the initial and final survey. Qualitative data analysis occurred by separating each free response into common themes. In both the initial and final survey free response questions were asked to better understand perspectives of the participants. The responses were categorized using Microsoft Excel into themes that were most commonly found.

\section{Results}

\section{Participants}

The Healthy Eating Program started with 40 participants and 26 (65\%) participants continued throughout the entire program. Of the 26 people who participated for all 25 weeks, 18 (69\%) completed both the initial and final surveys. If a participant missed three pickups they were removed from the program, and a person on the waiting list was added. This process helped eliminate any food waste and created more opportunities for people who wanted to take 
advantage of the program and bags of produce. There were 34 participants that filled out the initial survey and 29 participants that filled out the final survey. Of the 18 participants that completed both the initial and final surveys, the majority were female $(n=15,83.33 \%)$ versus male $(n=3,16.67 \%)$. The ethnicities of the 18 participants varied between Asian, White $(n=1$, 5.56\%), Black/African American ( $\mathrm{n}=3,16.67 \%)$, Black/African American, White ( $\mathrm{n}=4,22.22 \%)$, Hispanic/Latino $(\mathrm{n}=2,11.11 \%)$, Native American $(\mathrm{n}=1,5.56 \%)$ and White $(\mathrm{n}=7,38.89 \%)$. The number of people, including the participant, living in one household also varied between 1-2 household members ( $\mathrm{n}=5,27.78 \%$ ), 3-4 household members ( $\mathrm{n}=7,38.89 \%), 5-6$ household members $(\mathrm{n}=5,27.78 \%)$ and 6 or more household members $(\mathrm{n}=1,5.56 \%)$. Of the 18 participants that completed both the initial and final surveys, the majority said no they do not use SNAP benefits $(\mathrm{n}=10,55.56 \%)$ compared to those that said yes $(\mathrm{n}=8,44.44 \%)$. Alternatively, the majority said yes, they have visited a food pantry in the last three months ( $\mathrm{n}=11,61.11 \%$,) compared to those that said no $(\mathrm{n}=7,38.89 \%)$. Table 1 provides a visual representation of participant demographics.

\section{Results of Participants that Completed Both Surveys}

A paired samples t-test was conducted to determine if there were any significant differences from the initial survey to the post survey using the participants $(n=18)$ who completed the entire program and both initial and post surveys. Due to the small sample size, it was difficult to find significance among the surveys. Ten questions/statements were analyzed in this paired samples t-test. The statements and questions included: 1. On a typical day, how many serving of fruits and vegetable do you eat? 2. How many times did you make a

meal at home in the past week? 3. Do you consider yourself a healthy eater? 4. Food is stressful. 5. I worry about my family having enough food to eat. 6. I don't have time to cook healthy 
meals. 7. My grocery budget doesn't go far. 8. I don't know how to cook with fresh produce. 9. I feel healthy. 10. In the last week, I have skipped a meal. Three of the ten questions/statements showed significant at the .05 level.

For the question of do you consider yourself a healthy eater, the healthy eater scores increased from a mean of $3.06(s d=1.11)$ on the initial survey to a mean of $4.06(s d=.54)$ on the final survey. The difference between the two means was statistically significant at the .05 level, $\mathrm{t}(17)=-4.12$. The significance can be found in Table 2 .

For the statement I feel healthy, the feel healthy scores increased from a mean of 2.63 ( $s d$ $=1.04)$ on the initial survey to a mean of $3.72(s d=.83)$ on the final survey. The difference between the two means was statistically significant at the .05 level, $\mathrm{t}(17)=-.35$.

For the statement, in the last week, I have skipped a meal, the skipped a meal scores decreased from a mean of $2.28(s d=1.93)$ on the initial survey to a mean of $1.33(s d=1.61)$ on the final survey. The difference between the two means was statistically significant at the .05 level, $t(17)=2.32$. Results comparing the initial and final responses, both significant and insignificant findings, can be found in Table 2.

\section{Results of Final Survey}

Participants were asked what they liked about the Healthy Eating Program. The most common themes from the participants that completed the full program were 1. The vegetable bag introduced participants to new vegetables they had never tried before $(\mathrm{n}=18,33.33 \%), 2$. The vegetable bag always had a variety of fresh vegetables $(\mathrm{n}=18,27.78 \%)$, and 3 . The vegetable bag was free $(\mathrm{n}=18,11.11 \%)$. A participant stated, "I like the variety of vegetables, trying ones I wouldn't normally buy, trying new recipes, and getting farm fresh vegetables.” 
The participants $(n=18)$ who completed both surveys were asked to identify if there was any change in whether they cooked healthier meals since the start of the program. Participants could respond from the selection of no change, some change and big change. The results showed none of the participants reported no change $(\mathrm{n}=18,0.00 \%)$. There were 7 participants that reported some change $(\mathrm{n}=18,38.89 \%)$ and 11 participants reported big change $(\mathrm{n}=18,61.11 \%)$ in the consumption of healthier meals by the end of the program.

The participants $(n=18)$ who completed both surveys were asked to identify if there was any change in whether they ate more fresh produce regularly since the start of the program. Participants could respond from the selection of no change, some change and big change. The results showed none of the participants reported no change $(\mathrm{n}=17,0.00 \%)$. There were 8 participants that reported some change $(\mathrm{n}=17,47.06 \%)$ and 9 participants reported big change $(n=17,53.94 \%)$ in the consumption of more fresh produce by the end of the program.

The participants $(n=18)$ who completed both surveys were asked since the start of the program if they feel healthier in general. Participants could respond from the selection of no change, some change and big change. The results showed none of the participants reported no change $(n=17,0.00 \%), 7$ participants reported some change $(n=17,41.18 \%)$ and 10 participants reported big change $(\mathrm{n}=17,58.82 \%)$ regarding feeling healthier by the end of the program.

The participants $(n=18)$ who completed both surveys were asked if they purchase more fresh produce at the store since the start of the program. Participants could respond from the selection of no change, some change and big change. The results showed none of the participants reported no change $(\mathrm{n}=18,0.00 \%)$. There were 11 participants that reported some change $(\mathrm{n}=18$, $61.11 \%)$ and 7 participants that reported big change $(\mathrm{n}=18,38.89 \%)$ regarding buying more fresh produce at the store by the end of the program. 
The final survey asked participants "if this program is available, would you participate in the program next year?" Out of all the participants that completed the final survey $(n=29), 100 \%$ of the participants said yes, they would participate again.

\section{Discussion}

Food insecurity continues to be a devastating problem for low-income communities. This pilot program was created to determine if providing free CSA shares to residents in a lowincome community would improve their health status and reduce their daily food stressors. The study's results showed statistical significance on a few of the survey questions. When looking at the results from the paired samples T-test comparing the 18 participants that completed the entire program and completed both the initial and final surveys, the question: do you consider yourself a healthy eater, the statements: I feel healthy and I have skipped a meal in the last week all showed positive statistical significance. This data explains that the program did in fact have positive health benefits for the participants. This data coincides with a study from 2019 that compared health outcomes of vulnerable individuals receiving CSA shares versus those only receiving education. The results showed that CSA program interventions result in clinically meaningful improvements in diet quality (Berkowitz et al. 2019).

This data is important to note the potential that CSA programs have on health and food stress outcomes for CSA consumers. Research in food related well-being is growing in popularity and experts show that research participant's relationship with food and decreasing their overall stress and worry surrounding food is one way to reach a greater sense of food related wellbeing (Birtalan et al. 2020). Research also shows that the role of sustainable agriculture contributes to food-related well-being and is evident based on consumers' experience. It explains the relevance of psychological, social and spiritual aspects of food-related well-being 
beyond the nutritional characteristics of food in CSA (Birtalan et al. 2020). This explores the idea that a CSA program not only benefits the health of the consumers but also the overall wellbeing.

The data shows that logistics did not change for participants throughout the program. The statements: I cook at home more, I don't have time to cook healthy meals at home and my grocery budget doesn't go far did not significantly change. These results indicate that although CSA shares provide access, the logistics of cooking meals from scratch, having enough time, and subsidizing enough to make a difference in grocery budget did not change. This also is congruent with the fact that the drop off rate from the start of the program was high. Participants may have decided the bag was too much work or logistically they did not have time.

Initially the assumption going into this program was that fruit and vegetable consumption would increase due to the weekly vegetable bag. A study surveyed non-CSA members versus CSA members and found statistically significant increases in the fruit and vegetable consumption of CSA members (Cohen et al. 2012). The question asked at the initial and final survey, "on a typical day, how many servings of fruits/vegetables do you eat", did not lead to statistically significant results. This could be due to the small sample size or due to the question not being specific enough about what a serving size is.

Participants stated there was an increase in their consumption of healthier meals with $61.11 \%$ stating there was a big change in the number of healthier meals they cooked at home. Participants also felt healthier in general, $0 \%$ of the participants reported no change, $41.18 \%$ reported some change, and $58.82 \%$ reported big change in overall health. This is congruent with the data from past studies that being a part of a CSA program has the potential for positive impacts on food lifestyle behaviors and health outcomes (Allen et al. 2016). 
Based on the limited sample size, descriptive statistics was also used to provide perspectives from participants who completed the pilot program. The results detailed that there was an increase in vegetable consumption and trying new recipes at home. One participant stated, "I was able to try new recipes using the vegetables from the bags, in the past I bought pizza as the best choice but now I don't need to do that very often." Participants also reported on their improved health status. A participant stated, "my cholesterol went from 309 to 198 since the program started." Another participant mentioned, "I have experienced a greater desire to eat and prepare heathier meals. When I shop, I try to look for a variety of vegetables similar to what I find in the bags. Also, I have become less hesitant to explore new vegetables!" Overall, participant's responses were positive with the top three reasons they enjoyed the program being the variety of the bags each week, the fact that it was free and the benefits of introducing new produce. Past studies show similar data that a CSA member experience is generally satisfied, members report increased consumption of a variety of vegetables, and changes in the household food environment and meal pattern (Vasquez et al. 2017).

\section{Limitations}

The present study has several limitations. First, the sample size of participants who completed both the initial and final survey $(\mathrm{n}=18)$ was small and predominantly female (83.33\%). Thus, the applications of these finding to other populations is limited. A second limitation to this study was Covid-19. On March 13, 2020, Covid-19 was declared a National Emergency. In April 2020, 20.5 million jobs nationally were lost and fell disproportionately on minority groups, low-wage workers and people with no college education. By May 20, 2020, Illinois topped 100,000 reported Covid-19 cases (Chicago Tribune, 2020). These statistics likely impacted the results of the surveys and number of consistent participants that showed up each 
week. Participants would stop showing up due to illness, stress, fear and many other factors that were directly related to the pandemic. Results were also impacted by Covid-19. The results were based on self-reported data assessing health and food security, due to the pandemic, many other factors played a role in the participants' lives from the months of May to November.

Participant attrition was an issue as well in this study. Of the 40 original participants who were chosen from the original questionnaire, 26 of the participants stayed in the program from start to finish, and only 18 of those participants completed both surveys. Although encouraged, the participants were not forced to take the surveys in order to receive the vegetable bag, so some opted not to. Efforts such as incentives of gift cards and prizes were offered to participants who completed the surveys as a prior systematic review showed benefits of this (Singer \& Ye, 2012). Weekly reminders via email, Facebook posts and texts were also sent out to each participant reminding them of their pickup. One explanation for the lack of survey compliance and missing vegetable bag pickups could be the lack of access to smart phones or computers to receive the reminders. A final limitation to this study was that all information was self-reported by participants.

Future studies should attempt to utilize additional measures to assess health improvement such as incorporating a 24-hour food recall, anthropometric measures, and a mental health assessment form. Additionally, a participant of the program stated: "It would be helpful to have pictures with the names of each vegetable to correspond because certain vegetables I had never seen before and was unsure what they were." Another participant stated: "More recipes for more challenging vegetables would be helpful in the future." From this information, future studies should spend more time informing participants about how to cook and prepare the vegetables. 


\section{Conclusion}

The results obtained from this study identified the perceptions of residents living in a food desert on the impact of a community-supported agriculture pilot program. From the results of this study, future research opportunities can explore the long-term sustainability of a project similar to the Healthy Eating Program. CSA programs can improve overall health by decreasing stress and worry around food and increasing participants overall satisfaction of their health. CSA programs may be a sustainable intervention for food deserts, but further research needs to have larger sample sizes, more flexible logistics, and additional measures to assess health outcomes. 


\section{TABLES}

Table 1: Participant Demographics of those Completing the Entire Healthy Eating Program

\begin{tabular}{|c|c|c|}
\hline & \multicolumn{2}{|c|}{$\begin{array}{c}\text { Total Sample } \\
(n=18)\end{array}$} \\
\hline & $n$ & $\%$ \\
\hline \multicolumn{3}{|l|}{ Gender } \\
\hline Female & 15 & 83.33 \\
\hline Male & 3 & 16.67 \\
\hline \multicolumn{3}{|l|}{ Ethnicity } \\
\hline Asian, White & 1 & 5.56 \\
\hline Black/African American & 3 & 16.67 \\
\hline Black/African American, White & 4 & 22.22 \\
\hline Hispanic/Latino & 2 & 11.11 \\
\hline Native American & 1 & 5.56 \\
\hline White & 7 & 38.89 \\
\hline \multicolumn{3}{|l|}{ Household Members } \\
\hline $1-2$ & 5 & 27.78 \\
\hline $3-4$ & 7 & 38.89 \\
\hline $5-6$ & 5 & 27.78 \\
\hline $6+$ & 1 & 5.56 \\
\hline \multicolumn{3}{|l|}{ SNAP Benefits } \\
\hline Yes & 8 & 44.44 \\
\hline No & 10 & 55.56 \\
\hline \multicolumn{3}{|l|}{ Food Pantry } \\
\hline Yes & 11 & 61.11 \\
\hline No & 7 & 38.89 \\
\hline
\end{tabular}


Table 2: Initial Compared to Final Responses for Participants Completing Entire Program

\begin{tabular}{lccc}
\hline & \multicolumn{3}{c}{ Total Sample $(\mathrm{n}=18)$} \\
\cline { 2 - 4 } & $\begin{array}{c}\text { Difference } \\
\text { in mean }\end{array}$ & $\begin{array}{c}\text { Std. } \\
\text { Deviation }\end{array}$ & $\mathrm{p}$ \\
\hline FV Consumption & .000 & .594 & 1.000 \\
\hline Meal at Home & .278 & 1.018 & .263 \\
\hline Healthy Eater & -1.00 & 1.029 & .001 \\
\hline Stressful & .444 & 1.294 & .163 \\
\hline Worry & .389 & .850 & .069 \\
\hline No Time & .056 & .998 & .816 \\
\hline Small Budget & .389 & .979 & .110 \\
\hline Cook Produce & .556 & 1.338 & .096 \\
\hline Skipped Healthy & -.889 & 1.079 & .003 \\
\hline
\end{tabular}

$p=.05$ significance level 


\section{REFERENCES}

Allen JE, Rossi J, Woods T et al. (2016) Do community supported agriculture programs encourage change to food lifestyle behaviors and health outcomes? New evidence from shareholders. Int J Ag Sust 15, 70-82.

Aune D, Keum N, Giovannucci E et al. (2018) Dietary intake and blood concentrations of antioxidants and the risk of cardiovascular disease, total cancer, and all-cause mortality: a systematic review and dose-response meta-analysis of prospective studies. Am J Clin Nutr 100, 1069-1091.

Berkowitz SA, O’Neill J, Sayer E et al. (2019) Health center-based community supported agriculture: an RCT. Am J Prev Med 57, Suppl. 1, S55-S64.

Birtalan IL, Bartha A, Neulinger A et al. (2020) Community supported agriculture as a driver of food-related well-being. MDPI 12, 11.

Boeing H, Bechthold A, Bub A et al. (2012) Critical review: vegetables and fruit in the prevention of chronic diseases. Euro J Nutr 51, 637-663.

Chicago Tribune (2020) 6 months of COVID-19: Timeline of the outbreak and how politics, sports, entertainment and the economy changed.

https://www.chicagotribune.com/coronavirus/ct-viz-coronavirus-timeline-20200507uvrzs32nljabrpn6vkzq7m2fpq-story.html (accessed March 2021).

City of Bloomington (2020) About the city. https://www.cityblm.org/visitors/about-the-city (accessed March 2021).

City of Bloomington (2020) John M Scott grant. https://www.cityblm.org/Home/ShowDocument?id=24019 (accessed March 2021).

Cohen JN, Gearhart S \& Garland E (2012) Community supported agriculture: a commitment to a healthier diet. J Hunger \& Env Nutr 7, 20-37.

Data USA (2018) Bloomington, Illinois. https://atausa.io/profile/geo/bloomington-il (accessed March 2021).

Gundersen C \& Ziliak JP (2015) Food insecurity and health outcomes. Health Affairs 34, 11.

Hawthorne Valley (2014) CSA study. https://hvfarmscape.org/sites/default/files/csa_price_comparison_study.pdf (accessed March 2021).

Local Harvest (2020) Community supported agriculture. https://www.localharvest.org/csa/ (accessed March 2021). 
Singer E \& Ye C. The use and effects of incentives in surveys. Sage. Published online: 26 November 2012. https://doi.org/10.1177/0002716212458082.

United States Census (2020) Income, poverty and health insurance coverage in the United States: 2019. https://www.census.gov/newsroom/press-releases/2020/income-poverty.html (accessed March 2021).

USDA MyPlate (2020) Vegetables. https://www.myplate.gov/eat-healthy/vegetables (accessed March 2021).

Vasquez A, Sherwood NE, Larson N et al. (2017). Community supported agriculture as a dietary and health improvement strategy: A narrative review. J Acd Nutr \& Dietetics 117, 83-94.

World Health Organization (2021) Constitution. https://www.who.int/about/who-weare/constitution (accessed March 2021). 


\section{CHAPTER II: EXTENDED REVIEW OF LITERATURE}

\section{PERCEPTIONS OF RESIDENTS LIVING IN A FOOD DESERT ON THE IMPACT OF A COMMUNITY-SUPPORTED AGRICULTURE PILOT PROGRAM}

\section{Defining Food Desert Communities}

According to the USDA, a food desert can be defined by low income (poverty rate greater than or equal to $30 \%$ or median family income at $80 \%$ or lower of the area median family income) and one-third of the residents live more than 1 mile away (or 10 miles away in rural areas) from a supermarket (Dutko et al. 2012). This inability for residents in these areas to access affordable, healthy food options in close proximity also leads to barriers in the resident's overall health and development (Gunderson \& Ziliak, 2015). The term "food deserts" came from policy makers and researchers as they worked to improve health outcomes of those who live in areas with less access to healthy food and typically lower incomes (Widener \& Shannon, 2014).

According to the USDA report, it is estimated that 23.5 million people in the U.S. live in low-income areas that are at least one mile to the nearest large grocery store (Dutko et al. 2012). USDA's Economic Research Service identified more than 6,500 food desert tracts in the United States. From the USDA census, food desert tracts tend to have smaller populations, residents who have lower levels of education and income, and higher rates of unemployment. Additionally, areas with higher numbers of minority populations are more likely to be classified as food deserts (Dutko et al. 2012).

Dutko, Ver Ploeg, and Farrigan explained that poverty and minority populations are the greatest factors that determine low access to nutritional vendors. Low-income and minority populations are already less likely to have access to health care and fitness facilities; this 
compounded with limited access to healthy food, further contributes to the negative health outcomes for a community (Dutko et al. 2012). This data explains that concentrated poverty and minority populations, which often go hand in hand, emerge from the study as main factors for determining food desert communities.

\section{Impacts of Past Food Desert Interventions}

Access to food is important, but access to the right types of food and types of distributors is even more critical in food deserts. Research by Walker, Keane and Bourke (2010) reviewed 31 empirical studies that focused on food deserts in the United States and specifically explored race or ethnicity and income disparities within food deserts. They found that, generally, chain supermarkets were found in affluent areas whereas non-chain stores were in poor areas (Walker et al. 2010). Many big retailers do not want to open in low-income communities because it doesn't result in high profits for that storefront, so, as a result, convenience stores or dollar stores often pop up to fill the need. These small shops, however, do not provide nutritionally beneficial foods and are typically more expensive per item than larger supermarket options (Food Empowerment Project, 2010). Dollar stores, specifically, should not be a substitute for grocery stores because they rarely carry fresh produce. Additionally, these dollar stores typically employ fewer people than grocery stores and are typically low-wage and low-quality jobs, which do not enhance a community's socioeconomic status (Institute for Local Self-Reliance, 2018). Dollar stores are not the fix for food deserts and, as dollar stores continue to multiply, they will continue to contribute to the growing gap between high-income and low-income communities' access to fresh and affordable foods. 
In addition to the questionable results of simply providing access, there is also a negative socio-economic impact of adding large retailers to low-income communities. Vendors such as Walmart are expanding rapidly in rural and low-income food desert communities. Between 2015 to 2019, Walmart increased its retail units by 5.6 percent (Karpyn et al 2019), however it is shown that these big chains can do more harm to local business and employment rates (Institute for Local Self-Reliance, 2018).

Across all levels of government, there has been a push for building supermarkets in lowincome areas with poor access to large food retailers (Chrisinger, 2016). Researchers found that accessibility and convenience were big factors to determine why people would choose to go to supermarkets and, since dry goods can be between $10-40 \%$ less in chain stores than in non-chain stores (Walker et al. 2010) cost would be a substantial benefit for these low-income areas.

Between 2010-2015, the total number of grocery stores grew in both low-income and moderate/high-income communities according to the census tracts (Rhone et al. 2017). Despite the efforts made by national funds and public and private efforts to assist in alleviating the number of food deserts, there was unfortunately an overall increase in low-income areas in the US. This suggests that income and resource limitations are greater barriers to access healthy food retailers than proximity (Rhone et al. 2017). The census explains that close proximity to healthy food options is important, but in order to take advantage of the proximity, people need to have more resources to afford these foods.

A study in 2015 observed two communities that lived in food deserts over a span of three years. A total of 1,372 randomly selected households were observed and baseline data was taken in 2011, with follow-up data taken in 2014. In 2013, one neighborhood had a supermarket built. The researchers hypothesized that the (intervention) community with the new supermarket would 
have improved access to healthy foods and therefore the community satisfaction and health status would also improve (Dubowitz et al. 2015). The intervention neighborhood had a net positive change for overall dietary quality, total kilocalories, added sugars, solid fats, alcohol and added sugars, but there was not a net positive change in whole grain consumption, fruit and vegetable intake or body mass index. Although access was improved in the intervention community, there was not a progression of positive dietary changes or neighborhood satisfaction. Rather both communities' consumption of fruits and vegetables and overall health status declined over three years (Dubowitz et al. 2015). The researchers hypothesized that almost all residents from both communities continued with their shopping habits they had prior to the new supermarket as a possible explanation to these findings.

A study conducted by Chicago Booth examined whether a food desert was the root cause of poor health status. The study explains that exposing low-income households to the same products and prices as high-income households only reduces nutritional inequality by nine percent whereas the other ninety-one percent is driven by a difference in demand (Allcott et al. 2018). The study explains that new supermarkets have insignificant effects on healthy purchases at grocery stores, likely due to economic barriers faced by low-income households (Allcott et al. 2018), further illustrating that putting a supermarket in a food desert will help with accessibility to healthy food choices but does not correlate to healthy eating.

\section{Focusing on Health in Food Deserts}

Pan, Sherry, Njai and Blanck (2012) conducted a study that assessed the correlation between obesity and food insecurity. The study included 66,553 adults from 12 states. The study examined food insecurity with responses of always/usually/sometimes from the question "How often in the past 12 months would you say you were worried or stressed about having enough 
money to buy nutritional meals?" From these answers, logistic regression was used to examine the relatedness between obesity and food insecurity and the results showed the prevalence of obesity was $27.1 \%$ overall, $25.2 \%$ among food secure adults, and $35.1 \%$ among food insecure adults. Food insecure adults had 32\% increased odds of being obese and one in three food insecure adults were also obese (Pan et al. 2012). The findings from this study are congruent with other studies that show the necessity for increasing access to affordable and healthy foods for food insecure adults.

O’Neil, Keast, Fulgoni and Nicklas (2012) created a study to identify current food sources of energy and nutrients that adults consume most often with the goal of contributing to public health efforts to implement appropriate dietary recommendations. The population size of this study was 9,490, and the researchers analyzed 26 nutrients that were most often consumed by the participants to determine the food sources of energy (O'Neil et al. 2012). The researchers believed that it was important to understand current food selections in the US to enable public health officials to determine the optimal method for improving health outcomes in communities. The researchers found that a large portion of adult food consumption falls under low-nutrient food groups such as cakes, cookies, pies, and soft drinks (O’Neil et al. 2012). This research shows that people are more likely to consume foods that lack nutrients than they are to choose foods that are nutritionally dense. The pitfall of accessibility as the solution to food deserts is that even when people have access to grocery stores, they are not encouraged to eat healthy, they are just encouraged to eat more. The research conducted by O'Neil, Keast, Flugoni and Nicklas explains that food access does not equate to healthy food choices.

A 2019 study recruited 4,944 participants undergoing cardiac catheterization. The researchers placed the subjects in three categories depending on their residential addresses and 
whether they resided in a food desert community, low-income community, or both (Kelli et al. 2019). Subjects were followed for about three years and tracked for myocardial infarction and death. The researchers wanted to examine the association between myocardial infarction/death and living in low-income communities and/or food desert communities. The researchers found that living in food deserts brought greater health risks to a person, including an unfavorable cardiovascular risk profile, higher incidence of myocardial infarction and cardiovascular disease, and lower education level. The results indicated that adverse health impacts are not driven by access to healthy food but driven by area income in a food desert community. The overarching conclusion is that food deserts are detrimental to a community because of the disadvantages of the socioeconomic status of the neighborhood and the resulting lack of physical/social resources (Kelli et al. 2019).

Education, transportation, and affordability all need to be taken into account when considering how to improve nutrition centered health outcomes in a community that is in a food desert. Reduction in obesity may be due to other neighborhood or personal factors such as better access to parks or less psychological distress (Sheehan et al. 2017). A population-based study of 2,339 California mothers attempted to predict the likelihood of obesity based off of their neighborhood poverty trajectory (Sheehan et al. 2017). The measures taken included body mass index and obesity, long term neighborhood poverty class and inter-class mobility, and individual reported controls. Americans move frequently, which makes it difficult to classify neighborhoods and their effect on resident's health for the intent of this study. The researchers examined long-term neighborhood poverty trajectories but also accounted for short-term mobility when examining obesity among mothers (Sheehan et al. 2017). The findings show that mothers who live in neighborhoods that are consistently poor are more likely to be obese than 
mothers who live in neighborhoods or move to neighborhoods that have less long-term poverty (Sheehan et al. 2017).

Studies show that people who incorporate more fruits and vegetables in their diet on a regular basis are more likely to have a reduced risk of chronic disease (Aune et al. 2018; Boeing et al. 2012; USDA MyPlate, 2020). A systematic review of 95 studies were included in an analysis to determine fruit and vegetable intake and the risk of cardiovascular disease, total cancer and all-cause mortality (Aune et al. 2017). The results explained that an estimated 5.6 and 7.8 million premature deaths worldwide may be attributable to fruit and vegetable intake below 500 and $800 \mathrm{~g} /$ day, respectively. Increased fruit and vegetable intakes are associated with reduced risk of cardiovascular disease, cancer and all-cause mortality (Aune et al. 2017).

\section{Impact of Educational Information}

Jeewon and Pem (2015) completed a review of 100 relevant scientific articles that were linked with fruit and vegetable intake associated with reduced risk of chronic disease and body weight management. The data suggested that the intake of fruits and vegetables is inadequate in many countries. The researchers included that a number of the reviews from scientific articles confirmed that well planned and behavior-focused nutrition education intervention can considerably improve behavior and health indicators (Jeewon \& Pem, 2015). Multiple interventions are necessary to deliver information to ensure positive outcomes of increased fruit and vegetable intake.

SNAP-Ed is the nutrition education and obesity component of SNAP that aims to improve the chances that people who use SNAP will make healthier food choices (Long et al. 2013). Three SNAP-Ed projects evaluated the likelihood of increased fruit and vegetable intake post-nutrition education. Education included both direct and indirect education using different 
tools, depending on the age group. Two of the three projects studied low-income elementary school children and the other project focused on senior citizens who use SNAP. The SNAP-Ed studies found that the participants increased their daily fruit and vegetable consumption at home and were more likely to choose low fat free milk after receiving nutrition education (Long et al. 2013).

In 2010, a cross-sectional survey was completed covering 228 urban census tracts in Los Angeles County and Southern Louisiana. There were 2,767 people who completed a one-day diet recall which estimated their calories from fruit, vegetables, cookies, candy, salty snacks, sweetened soda, and alcohol (Cohen et al. 2010). The results showed there was a considerable overconsumption of unhealthy calories compared to the underconsumption of fruits and vegetables (Cohen et al. 2010). The findings suggest that although pushing for more physical activity and fruit and vegetable consumption is important, it may be less effective in combating childhood obesity than pushing for the decrease in unhealthy food consumption (Cohen et al. 2010).

\section{New Efforts in Food Deserts}

Recently, new programs that involve local fresh produce like Community Supported Agriculture (CSA) programs have been put in place to try to improve healthy food access within food desert communities. CSA programs provide fresh produce that help the community and, as a result, may be a great option for low-income communities to get increased access to healthful foods.

Community Supported Agriculture (CSA) programs help bridge the gap for people to consume more fruit and vegetables in their day to day lives. CSA programs have become popular in recent years as an avenue to improve the health status of consumers. Within the programs, 
consumers would have the ability to buy shares of a farm's harvest in advance, which leads to many benefits for both farmers and consumers. Farmers benefit by earning payment early in their season, which not only helps with the farm's cash flow, but also provides an opportunity to create a strong sense of community by getting to know their consumers (Local Harvest, 2020). Consumers benefit by not only getting to try new vegetables and recipes, but also by having a constant source of fresh produce which provides nutritional benefits. In 2002, the number of US farms selling directly to consumers was 116,733 . By 2012 , the number increased to 144,530 (Low et al. 2015). Unlike chain stores, local farmers markets have a positive impact on providing jobs to the communities and other regions while also providing locally grown food (Low et al. 2015).

Cohen, Gearhart and Garland (2012) conducted a study which surveyed 10,000 individuals who were affiliated with a CSA promoting organization called Just Food in New York City. From the 10,000 individuals, 1,278 returned the initial survey and 583 completed the initial and follow-up surveys. The surveys examined whether CSA participation correlates an increase in the consumption of fruit and vegetables and if the amount of home cooked meals increased due to the CSA shares (Cohen et al. 2012). When the 583 completed surveys were analyzed, the CSA members showed a statistically significant increase in fruit and vegetable consumption of 2.2 servings per week and 4.9 home cooked meals compared to the CSA nonmember (Cohen et al. 2012).

CSA programs provide fresh produce directly to the consumer, which eliminates the need to purchase processed foods often found in grocery stores. A 2016 study surveyed 151 participants in CSA programs near Lexington, Kentucky (Allen et al. 2016). The researchers asked 20 questions that could be assessed using paired two-sided t-tests. In the surveys, the 
researchers questioned socioeconomic factors, self-reported health status, and collected data about years of CSA enrollment. The results suggested that being part of a CSA program has the potential for positive impact on food lifestyle behaviors and health outcomes. The researchers suggested that this was promising for future studies to analyze how CSA participation can improve behaviors and health outcomes (Allen et al. 2016).

A program developed in 2006 called "The Food Project's Lynn Central Square Farmers' Market" was one of the first in the United States to accept SNAP benefits electronically (Food Project, 2017). The program developed into Boston Bounty Bucks program and then in 2017 inspired the Healthy Incentives Program (HIP). Healthy Incentives Program SNAP recipients can receive extra SNAP benefits for every dollar spent on a CSA share or at a farmers' market. The current CSA Pilot program occurring in Massachusetts operates under a waiver from USDA (Food Project, 2017). The program encourages fresh produce consumption and incentivizes participants to buy local.

Additionally, a study in 2016 was designed to establish if participation in a farmers' market incentive pilot program had an impact on food security and fruit and vegetable intake (Savoie-Roskos et al. 2016). Similar to HIP, people participating in SNAP were eligible to receive a dollar-per-dollar match up to farmers' market incentives. From the pretest - posttest design which measured intake and status of the participants food security, fewer individuals reported experiencing food insecurity-related behaviors and a significant increase was found of intake in certain vegetables (Savoie-Roskos et al. 2016).

A recent study completed in 2019 analyzed the motivation, barriers, and methods of advertisement used to influence people to participate in CSA programs (Chen et al. 2019). A national survey went out with 795 responses and the responses were divided by past CSA 
membership, current CSA membership and future CSA membership. The study emphasized reasons that people stay in a CSA program and barriers which led to people leaving a CSA program. The results showed those in a younger generation, part of a higher-income family, and people who support sustainable agriculture are most likely to have a current CSA membership. The current and future membership results found several significant barriers, mainly the ratio of value to cost of the shares (Chen et al. 2019). The cost of CSA shares may be the largest barrier for low-income households to participate in CSA programs.

An average CSA share per pick-up is \$22.28 (Hawthorne Valley, 2014). Typically, a consumer must pay upfront for the entire season which lasts about 22-26 weeks depending on the farm. This puts the price at about $\$ 500-\$ 600$ per share (Hawthorne Valley, 2014) which is out of reach for people of many low-income communities. Although CSA programs provide benefits for the people in the community who can afford them, unfortunately residents in low-income communities rarely can. Recently, cost-offset (CO) CSA programs have become popular as a way to offset the hefty cost of the share.

A study worked with 53 low-income families who had a CO-CSA program in place, so the participants only paid for half of the shares. The main challenges reported were meal planning despite preparation advice, unfamiliar foods, and quick spoilage (White et al. 2018). The researchers concluded that CO-CSA helps facilitate increased access to fresh produce for low-income families, however, having fruits and vegetables does not correlate to better health outcomes because there are still barriers such as time, kitchen skills, and food preference (White et al. 2018). This is valuable information for future research to understand the complexities of having a CSA share and how to benefit the families while mitigating the challenges presented by CSA programs that have been shown from previous studies. 
A study in 2017 examined fruit and vegetable intake in low-income households of participants who were part of a 50\% subsidized CSA program (Hanson et al. 2017). CSA participants paid upfront for their share and received the produce weekly throughout the season, typical for a CSA program. The researchers surveyed the 41 participants twice with only 23 participants responding in the second survey. In the study, researchers reported that the total fruit and vegetable intake for CO-CSA participants was greater than the US average, and typically met recommendations for consumption of vegetables (Hanson et al. 2017). The researchers suggested that the CO-CSA model needs further examination for its implications on health in low-income households (Hanson et al. 2017).

Eating more fruits and vegetables reduces one's risk of disease, increases nutrients in one's diet, and helps maintain body weight (Moore \& Thompson, 2015). There has been an increase in farmers markets, CSA programs, and initiatives to serve nutritious foods to lowincome communities in order to provide more access to fruits and vegetables, however, there is still lower than recommended fruit and vegetable consumption in the United States. Between 2007-2010, half of the US population consumed less than 1 cup of fruit and less than 1.5 cups of vegetables daily (Moore \& Thompson, 2015). Across all states, continued efforts need to be made in order to increase demand and consumption - specifically in low-income communities (Moore \& Thompson, 2015).

Food insecurity remains a catastrophic problem among low-income communities. The greatest challenge however is poor dietary quality. According to the USDA in 2015, almost all people in the US fail to meet their needs for whole grains, $80 \%$ do not get enough fruits, and $90 \%$ of Americans do not consume enough vegetables. As opposed to saturated fat and refined grains which $70 \%$ of the US eats more than recommend and $90 \%$ of the population consumes too 
much added sugar (USDA Dietary Guidelines, 2015). New interventions that incorporate education and access to healthy produce need to be put in place to create sustainable change for low-income food desert communities. Interventions such as community supported agriculture programs may be the solution for bridging the gap between health status and low-income communities. 


\section{REFERENCES}

Allen JE, Rossi J, Woods T et al. (2016) Do community supported agriculture programs encourage change to food lifestyle behaviors and health outcomes? New evidence from shareholders. Int J Ag Sust 15, 70-82.

Allcott H, Diamond R, Dube JP et al. Food deserts and the causes of nutritional inequality. National Bureau of Economic Research. Published online December 2017. doi: $10.3386 / \mathrm{w} 24094$

Aune D, Giovannucci E, Boffetta P et al (2017) Fruit and vegetable intake and the risk of cardiovascular disease, total cancer and all-cause mortality - a systematic review and dose-response meta-analysis of prospective studies. Int J Epi 46, 1029-1056.

Aune D, Keum N, Giovannucci E et al. (2018) Dietary intake and blood concentrations of antioxidants and the risk of cardiovascular disease, total cancer, and all-cause mortality: a systematic review and dose-response meta-analysis of prospective studies. Am J Clin Nutr 100, 1069-1091.

Boeing H, Bechthold A, Bub A et al. (2012) Critical review: vegetables and fruit in the prevention of chronic diseases. Euro J Nutr 51, 637-663.

Chen J, Gao Z, Chen X et al. (2019) Factors affecting the dynamics of community supported agriculture membership. Sustainability 11, 4170.

Chrisinger B (2016) A mixed-method assessment of a new supermarket in a food desert: contributions to everyday life and health. J Urban Health 93, 425-437.

Cohen DA, Sturm R, Scott M et al. (2010) Not enough fruit and vegetables or too many cookies, candies, salty snacks, and soft drinks? Sage 125, 88-95.

Cohen JN, Gearhart S \& Garland E (2012) Community supported agriculture: a commitment to a healthier diet. J Hunger \& Env Nutr 7, 20-37.

Dubowitz T, Ghosh Dastidar M, Cohen DA et al. (2015) Diet and perceptions change with supermarket introduction in a food desert, but not because of supermarket use. Health Affairs 34, 11.

Dutko P, Ver Ploeg M \& Farrigan T (2012) Characteristics and influential factors of food deserts. USDA Economic Research Service 140, 1-29.

Food Empowerment Project (2010) Shining a light on the valley of heart's delight. https://foodispower.org/wp-content/uploads/2013/04/FEP_Report_web_final.pdf (accessed March 2021).

Gundersen C \& Ziliak JP (2015) Food insecurity and health outcomes. Health Affairs 34, 11. 
Hanson KL, Kolodinsky J, Wang W et al. (2017) Adults and children in low-income households that participate in cost-offset community supported agriculture have high fruit and vegetable consumption. Nutrients $\mathbf{9}, 726$.

Hawthorne Valley (2014) CSA study. https://hvfarmscape.org/sites/default/files/csa_price_comparison_study.pdf (accessed March 2021).

Institute for Local Self-Reliance (2018) The impact of dollar stores and how communities can fight back. https://ilsr.org/dollar-stores-factsheet/ (accessed March 2021).

Karpyn A, Riser D, Tracy T et al. (2019) The changing landscape of food deserts, UNSCN Nutr 44, 46-53.

Kelli HM, Kim JH, Tahhan AS et al. (2019) Living in food deserts and adverse cardiovascular outcomes in patients with cardiovascular disease. $J$ Am Heart Assoc 8, 4.

Local Harvest (2020) Community supported agriculture. https://www.localharvest.org/csa/ (accessed March 2021).

Long V, Cates S, Blitstein J et al. (2013) Supplement nutrition assistance program education and evaluation study (Wave II). USDA Food \& Nutr Service, 1-64.

Low SA, Adalja A, Beaulieu E et al. (2015) Trends in US local and regional food systems. USDA Economic Research Service, 68, 1-64.

Moore LV \& Thompson FE (2015) Adults meeting fruit and vegetable intake recommendations - US, 2013. CDC 64, 709-713.

O’Neil CE, Keast DR, Fulgoni VL et al. (2012) Food sources of energy and nutrients among adults in the US: NHANES 2003-2006. Nutrients 4, 2097-2120.

Pan L, Sherry B, Njai R et al. (2012) Food insecurity is associated with obesity among US adults in 12 states. J Acad Nutr \& Dietetics 12, 1403-1409.

Pem D, \& Jeewon R (2015) Fruit and vegetable intake: Benefits and progress of nutrition education interventions - narrative review article. Iran J Pub Health 44, 1309-1321.

Rhone A, Ver Ploeg M, Dicken C et al. (2017) Low-income and low-supermarket-access census tracts, 2010-2015. USDA Economic Research Service 165, 1-15.

Savoie-Roskos M, Durward C, Jeweks M et al. (2016) Reducing food insecurity and improving fruit and vegetable intake among farmers' market incentive program participants. $J$ Nutr Edu and Behavior 48, 70-76. 
Sheehan CM, Cantu PA, Powers DA et al. (2017) Long-term neighborhood poverty trajectories and obesity in a sample of California mothers. Health \& Place 46, 49-57.

The Food Project (2017) SNAP, HIP, and other food assistance. https://thefoodproject.org/snaphip/ (accessed March 2021).

USDA MyPlate (2020) Vegetables. https://www.myplate.gov/eat-healthy/vegetables (accessed March 2021).

USDA Dietary Guidelines (2015) Scientific report of the 2015 dietary guidelines advisory committee. https://health.gov/sites/default/files/2019-09/Scientific-Report-of-the-2015Dietary-Guidelines-Advisory-Committee.pdf (accessed March 2021).

Walker R, Keane C \& Burke J (2010) Disparities and access to healthy food in the United States: A review of food deserts literature. Health \& Place 16, 5.

White MJ, Jilcott Pitts SB, McGuirt JT et al. (2018) The perceived influence of cost-offset community-supported agriculture on food access among low-income families. Pub Health Nutr 21, 2866-2874.

Widener MJ \& Shannon J (2014) When are food deserts? Integrating time into research on food accessibility. Health \& Place 30, 1-3. 


\section{APPENDIX A: QUESTIONNAIRE FOR INTERESTED PARTICIPANTS OF HEALTHY}

\section{EATING PROGRAM}

Thank you for your interest in our new Healthy Eating Program. Funded by a generous grant from the John M Scott Health Commission, this program provides new healthy eating options for low-income, Westside families. Your family can receive a pre-packaged box of free organic vegetables once per week for the farmers' market season (mid-May through mid-October). To get started, please answer this short survey. Someone from the WBRP will call you to complete the registration. Surveys are due by April 17 at noon. If you are interested in the free Veggie Box, pickup will be at the WBRP (724 W Washington) on Tuesday nights from 6-8pm.

If you have any questions, please contact food@westbloomington.org or call 309-829-1200. Thank you!

1. This program provides a free box of fresh, organic vegetables from PrairiErth farm once per week for the season (mid-May through mid-October). Would you like to sign up for the Free Veggie Box?

1. Yes

2. No

3. Maybe Later

2. You or someone you identify MUST pick up the Free Veggie box on Tuesday nights between 6-8 pm at the WBRP Office (Washington \& Allin). Will you be able to pick up the Free Veggie Box weekly?

1. Yes

2. No

3. Maybe

3. What questions or concerns do you have about this program? When we call you to finish registering you for the program, we will answer all questions that you have.

Tell us about yourself and your family. The program is funded by a grant that limits participation to low-income, Westside families.

4. Name:

5. Street Address:

6. Email:

7. Phone number:

8. Best time to reach you:

9. How many people live in your house? (Please enter total number $=$ you + other members)

10. What is your approximate monthly household income?

11. To help us provide you with the best program possible, are you willing to participate in a research project about healthy eating habits of families that live in "food deserts" like the Westside? This project would include additional surveys (via phone or email) over the summer.

1. Yes

2. I would like to know more

3. No 
12. What is your race/ethnic background? (This question is optional and used only for grant reporting purposes)

1. Hispanic/Latino

2. American Indian

3. Asian

4. Black/African American

5. Native American

6. White

7. Other

A member of the WBRP Healthy Eating committee will follow up with you regarding the program. We will call you at the phone \# above. Thank you for your interest. If you have any questions, please contact food@westbloomington.org or call 309-829-1200. 


\section{APPENDIX B: INITIAL SURVEY}

Thank you for assisting us with research for the Healthy Eating program. By answering these surveys, the program organizers will learn how to better meet the health and nutrition needs of Westside families. The first question on the survey is called "Informed Consent" and every university uses forms like this one to make sure that research participants understand how the research will happen.

This is the initial survey. You can skip any of the questions in this survey. If you ever have any questions about the research or about the program,you can email food@westbloomington.org

This survey contains 16 questions and will take about 15 minutes to complete. If you prefer for someone to read you the survey, please contact us.

1. How are you participating in the Healthy Eating Program?

- Receiving a free vegetable box

- Receiving a free vegetable box with the incentive of free Walmart grocery delivery

2. Have you ever participated in a CSA program before? The Free Veggie Box is an example of a Community Supported Agriculture (CSA) program. CSA is a method to buy local, seasonal produce directly from a farmer by paying up front and receiving a "share" of the farm's produce every week.

- Yes

- No

3. If you are not interested in the free grocery delivery option, why?

- I don't shop at Wal-Mart

- I don't spend \$30 per shopping trip

- I have never done online shopping and I'm not sure about it

- I don't have a credit/debit card

- Other

4. Tell us why you are interested in the WBRP Healthy Eating Program:

5. On a typical day, how many servings of fruits/vegetables do you eat?

- None

$-\quad 1-2$

- $3-5$

- Over 5

6. What are your favorite fruits or vegetables?

7. Do you agree or disagree with these statements: Each statement can be answered with strongly disagree, disagree, neither agree nor disagree, agree, strongly agree

- I am a healthy eater

- Eating out is easier than cooking at home

- It is hard to get to and from the grocery store

- Food is stressful for me

- I don't know how to cook with fresh produce

- I like to try new foods and new recipes

- I worry about my family having enough food to eat

- I don't have time to cook healthy meals at home 
- My grocery budget doesn't go very far

- I feel healthy

- If there was one, I would shop at a grocery store on the Westside

8. Thinking about your meals in the last three days, how many times did you: Each statement can be answered with a number 0,1,2,3, 4, 5+

- Make a meal at home

- Get take-out/ delivery

- Ate at a restaurant

- Skipped a meal

- Ate a free meal that was provided with work

9. Where do you make your healthiest food choices?

- Home

- Take-out/ delivery

- Restaurant

10. What influences your decision about where and when to eat?

- Fast

- Healthy

- Easy

- Cheap/ free

- Enjoy the taste

11. How do you usually get to the grocery store?

- Car

- Bus

- Bike

- Walk

- It depends

- Other

12. How many times a month do you shop for groceries?

$-1$

$-2$

$-3$

- 4 or more

13. How do you most commonly buy your vegetables?

- Fresh

- Canned

- Frozen

14. Have you visited a food pantry in the last three months?

- Yes

- No

15. Do you visit the farmers' market in Downtown Bloomington?

- Regularly

- Sometimes

- Never

16. Do you use SNAP benefits (like a debit card to help purchase food)?

- Yes

- No 
- Not sure

- I would like information about this program 


\section{APPENDIX C: FINAL SURVEY}

Thank you for taking the final survey. We appreciate your time and welcome your feedback. You can skip any of these questions. If you need to reach someone in the WBRP Healthy Eating Program, you can always email Food@WestBloomington.org.

The first question is an informed consent form, please sign and date it.

There are 23 questions in the survey, the survey should take about 15 minutes. Your feedback will be used to improve the program in the future and for research purposes. Thank you for your time.

1. How many people live in your house?

- $1-2$

$-\quad 3-4$

- $\quad 5-6$

- More than 6

2. What is your race/ethnic background?

- Hispanic/Latino

- American Indian

- Asian

- Black/African American

- Native American

- White

- Other

3. On a typical day, how many servings of fruits/vegetables do you eat?

- None

$-\quad 1-2$

- $\quad 3-5$

- Over 5

4. Since the start of the program, how have your eating and cooking routines changed? Each statement can be answered with no change, some change, big change

- $\quad$ Eat more fresh produce

- Cook at home more

- Eat out less

- Eat regular meals every day

- Cook healthier meals

- Worry less about having enough food to eat

- Feel healthier

- $\quad$ Buy more fresh produce at the store

5. Tell us about any of these changes:

6. Did you use Walmart free grocery delivery as part of the incentive program?

- Yes

- No

7. If yes, how often did you use the free grocery delivery instead of going to the store?

- I rarely used the free grocery delivery 
- I use the free grocery delivery half the time and go to the store half the time

- I use the free grocery delivery most of the time

8. Tell us about any issues or benefits you had using the free grocery delivery:

9. Do you agree or disagree with these statements: Each statement can be answered with strongly disagree, disagree, neither agree nor disagree, agree, strongly agree

- I am a healthy eater

- Eating out is easier than cooking at home

- It is hard to get to and from the grocery store

- Food is stressful for me

- I don't know how to cook with fresh produce

- I like to try new foods and new recipes

- I worry about my family having enough food to eat

- I don't have time to cook healthy meals at home

- My grocery budget doesn’t go very far

- I feel healthy

- If there was one, I would shop at a grocery store on the Westside

10. Thinking about your meals in the last week, how many times did you: Each statement can be answered with a number $0,1,2,3,4,5+$

- Make a meal at home

- Get take-out/ had food delivered

- Ate at a restaurant

- Skipped a meal

11. Where do you make your healthiest food choices?

- Home

- $\quad$ Take out/ delivery

- Restaurant

12. What influences your decision about where and when to eat?

- Fast

- Healthy

- Easy

- Cheap/ free

- Enjoy the taste

13. How many times a month do you shop for groceries or get groceries delivered?

- 1

- 2

- 3

- 4 or more

14. About how much money do you normally spend on your groceries in a month?

- \$10-\$50

- $\$ 50-\$ 100$

- $\$ 100-\$ 200$

- $\$ 200-\$ 300$

- $\$ 300-\$ 400$

- More than $\$ 400$

15. Rank the type of vegetables you buy: $1=I$ buy majority this way, $3=I$ buy the least amount of vegetables this way 
- Fresh

- Canned

- Frozen

16. Have you visited a food pantry in the last three months?

- Yes

- No

17. Do you visit the farmers' market in downtown Bloomington?

- Yes

- No

18. Do you use SNAP benefits (like a debit card to help purchase food)?

- Yes

- No

- Not sure

19. Did you participant in any other WBRP programs while you were part of the Healthy Eating Program?

20. What did you like about the Healthy Eating Program?

21. What changes would you make to the Healthy Eating Program?

22. If this program is available, would you participate in the program next year?

- Yes

- No

- Maybe/ not sure

23. Final questions, comments, concerns? We appreciate your feedback! 


\section{APPENDIX D: RECRUITMENT EMAIL}

The WBRP is proud to announce a new Healthy Eating Program!

The West Bloomington Revitalization Project (WBRP) wants Westside families to eat more fresh produce and be healthy. Supported with a grant from the John M Scott Health Commission, the WBRP will provide forty eligible Westside residents a free box of fresh, organic vegetables every week through the 2020 Farmers' Market season.

We recognize that the Westside has been designated as a USDA food desert. This means residents face challenges getting to and from grocery stores that carry healthy food options.

Forty families will receive a box of fresh, organic vegetables from PrairiErth Farm.

Get a free box every week for 24 weeks starting in mid-May

Must be able to pick up from WBRP office every Tuesday 6-7pm

Only one box per family/address

This program is generously funded by a grant from the John M Scott Health Commission and participation is limited to families that are low-income and live on the Westside.

If you are interested in the program, please complete this initial survey attached. It will also ask additional questions about you and your family's eating habits. If you qualify, a member of our planning team will follow up to enroll you in the program. 


\title{
APPENDIX E: INFORMED CONSENT
}

\author{
Illinois Wesleyan University Institutional Review Board Informed Consent Form \\ Healthy Eating in the Westside Food Desert \\ Deborah Halperin \& Tera Wilson, Illinois Wesleyan University \\ Jacqueline Schumacher \& Jesi Thome, Illinois State University
}

\section{INTRODUCTION}

You are invited to be a participant in a research study about healthy eating in the Westside food desert. You are eligible for this program because you are enrolling in the West Bloomington Revitalization Project (WBRP) Healthy Eating Program. We ask that you read this document and ask any questions you may have before agreeing to be in the study. The study is being conducted in partnership by the Illinois Wesleyan University Action Research Center and the Health \& Nutrition Department at Illinois State University.

\section{BACKGROUND}

Food deserts presents challenges for families to access healthy food options. The purpose of this study is to determine if families living in a food desert can benefit from participation in a community-supported agriculture (CSA) program or free grocery delivery.

\section{DURATION}

The WBRP Health Eating Program runs for one year. We will ask you to complete a survey now (March - April 2020), in the middle of the program (July 2020), and then at the end of the program (October 2020). Each survey should take about fifteen minutes to complete. You will be invited to participate in a focus group over the summer (August 2020), which will take no longer than one hour.

\section{PROCEDURES}

If you agree to be in this study, you must read and sign this consent form before you complete the survey(s) or participate in the focus group. The survey can be read to you if that makes it easier to complete. You do not have to answer all the questions if you do not wish to, and you may withdraw from this study at any time. Your name will not otherwise be associated with this data in any way it is used in the future.

\section{RISKS/BENEFITS}

This study has the following risks: You may feel discomfort or difficulty in explaining or discussing your eating and shopping habits as well as your family's income level. The benefits of participation include increased understanding of healthy eating habits and the support for new strategies to help families that live in food deserts.

\section{CONFIDENTIALITY}

The records of this study will be kept private. Your name will never be associated with your answers in any report or presentation that is given based on the data collected. Any paper surveys will be stored under lock and key in Deborah Halperin's office at IWU and electronic copies of 
the survey will be held in a password protected account. Research reports will only present findings on a group basis, without any personally identifying information.

\section{VOLUNTARY NATURE OF THE STUDY}

Your participation in this study is voluntary. Your decision whether or not to participate will not affect your current or future relations with the WBRP, IWU, ISU, or any of its representatives. You have the right to refuse to participate or to withdraw at any time without penalty of loss of benefits. In other words, you can continue to receive your veggie boxes or grocery delivery.

\section{CONTACTS AND QUESTIONS}

At any time, you may ask any questions you have about this study or about the informed consent process. If you have questions or concerns regarding this study and would like to speak with someone other than the researcher(s), you may contact the Institutional Review Board Chair, Illinois Wesleyan University, at 309-556-1000 and irb@iwu.edu.

\section{STATEMENT OF CONSENT}

You will be given a copy of this form to keep for your records.

I have read and understood the above explanations, and my questions have been addressed. The information that I provide will be used for research purposes only. I understand that my participation is voluntary and that I may withdraw anytime without penalty. If I have any concerns about my experience in this study (e.g., that I was treated unfairly or felt unnecessarily threatened), I may contact the researcher or the Chair of the IWU Institutional Review Board regarding my concerns. I affirm that I am at least 18 years of age, and I voluntarily consent to participate in this research study.

\section{Participant signature:}

Date:

Print name:

Signature of Person Obtaining Consent:

Date:

Print name: 